\title{
Mechanisms of Orthopnea in Stable Obese Subjects
}

\author{
Emilie Perino MD, Pascale Nesme MD, Michèle Germain MD, and Claude Guérin MD PhD
}

\begin{abstract}
BACKGROUND: The present study explored the role of closing volume as a determinant of orthopnea in stable obese subjects. We hypothesized that: (1) increase in closing volume in supine position would be greater in orthopneic than in non-orthopneic subjects, and (2) the relationship of change in closing volume to change in dyspnea with position would be dependent on expiratory flow limitation in the sitting position. METHODS: In stable obese subjects, in sitting and supine positions, we measured the Borg dyspnea score, static lung volumes, expiratory flow limitation during tidal breathing, and single-breath nitrogen expiration test. From the latter, we determined closing volume and closing capacity, slope of phase III, and opening capacity. Orthopnea was defined as any increase in the Borg score in the supine position from its value in the sitting position. RESULTS: Twenty-one subjects (13 women), median age (interquartile range) $55(49-57)$ y and with body mass index of $39(38-42) \mathrm{kg} / \mathrm{m}^{2}$ were included, of whom 12 were orthopneic and 11 had expiratory flow limitation while seated. In the sitting position, orthopneic and non-orthopneic subjects were similar for age, body mass index, and pulmonary function tests, including single-breath nitrogen expiration test-derived variables. In the orthopneic subjects, there were no changes in any respiratory variable between positions. In the non-orthopneic subjects, there was a significant decrease in slope of phase III in the supine position from $1.67(1.33-3.60)$ to $1.40(1.25-1.66) \% / L(P=.008)$. Overall, the subjects' Borg score significantly correlated with the slope of phase III $(r=0.63, P=.002)$ and opening capacity $(r=-0.47, P=.03)$. In 10 subjects without expiratory flow limitation, it correlated with slope of phase III $(r=0.68, P=.03)$. CONCLUSIONS: In stable obese subjects, magnitude of orthopnea correlated with an increase in the slope of phase III in subjects without expiratory flow limitation. Expiratory flow limitation should be taken into account in obese patients. Key words: closing volume, expiratory flow limitation, obesity, orthopnea. [Respir Care 2016;61(8):1015-1022. (C) 2016 Daedalus Enterprises]
\end{abstract}

\section{Introduction}

The prevalence of obesity and being overweight increased worldwide from 28.8 to $36.9 \%$ in men and from

\footnotetext{
Drs Perino and Guérin are affiliated with Réanimation médicale, Hôpital de la Croix Rousse, Hospices Civils, Lyon, France. Dr Guérin is also affiliated with Université de Lyon, Lyon, France and IMRB INSERM U955 Eq13, Créteil, France. Dr Nesme is affiliated with the Service de Pneumologie, Hôpital de la Croix Rousse, Hospices Civils, Lyon, France. Dr Germain is affiliated with the Laboratoire d'explorations fonctionnelles respiratoires Hôpital de la Croix Rousse, Hospices Civils, Lyon, France and Université de Lyon, Lyon, France.
}

The authors have disclosed no conflicts of interest.

Supplementary material related to this paper is available at http:// www.rcjournal.com.
29.8 to $38.0 \%$ in women between 1980 and $2013 .{ }^{1}$ In 2011-2012 in the United States, 34.9\% of adults age 20 y or older were obese. ${ }^{2}$ A systematic review and meta-analysis found that obesity was a significant risk factor for all-cause mortality. ${ }^{3}$ Most of the investigations done in obese subjects have focused on cardiac and metabolic findings. In terms of its respiratory impact, it is well known that obesity is a risk factor for the occurrence ${ }^{4}$ and severity of asthma. Obesity is also a risk factor for obstructive sleep apnea (OSA). ${ }^{5}$ Obesity, especially if severe, can also

\footnotetext{
Correspondence: Claude Guérin MD PhD, Réanimation médicale, Hôpital de la Croix Rousse, Hospices Civils, 103 Grande Rue de la Croix Rousse, Lyon 69004, France. E-mail: claude.guerin@chu-lyon.fr.
}

DOI: $10.4187 /$ respcare. 04146 
be associated with a specific type of alveolar hypoventilation, namely obesity-hypoventilation syndrome. ${ }^{6}$ In obese subjects investigated in the sitting position, the static lung volumes, in particular functional residual capacity (FRC) and expiratory reserve volume (ERV), are lower than normal values. ${ }^{7}$ Breathlessness is common during exercise in

\section{See the Related Editorial on Page 1133}

obese patients ${ }^{8}$ but may also be present at rest. Little is known about the prevalence and mechanisms of orthopnea in obesity. A better understanding of the effects on obese patients of changing position from sitting to supine is important because the supine position is standard for sleep. The findings regarding the change in FRC and position vary between studies, with some investigators finding no change ${ }^{9,10}$ and others ${ }^{11}$ finding a decrease in the supine compared with the sitting position. One reason for these discrepancies between studies may relate to whether closing volume is taken into account. In 7 obese subjects, the closing capacity/FRC ratio significantly decreased in the sitting compared with the supine position. ${ }^{11}$ In this study, dyspnea was not measured. In morbidly obese subjects, Ferretti et al ${ }^{12}$ found that orthopnea correlated with expiratory flow limitation while supine, but they did not measure closing volume.

Therefore, the objective of the present study was to assess the relationships between orthopnea and change in closing volume in the sitting compared with the supine position, in obese subjects, taking into account expiratory flow limitation. We hypothesized that: (1) closing volume would increase in the supine position in subjects with orthopnea but would not increase, or not increase to the same extent, in subjects without orthopnea, and (2) the relationship of orthopnea to closing volume would be dependent on expiratory flow limitation while sitting. Should the first hypothesis be true, the lung should be kept open by using positive-pressure ventilation. Should it be wrong, other mechanisms, notably cardiac failure, should be ruled out. If the second hypothesis is true, assessment of expiratory flow limitation should be done routinely in pulmonary function testing laboratories.

\section{Methods}

\section{Subjects}

The subjects were recruited from out-patients with obesity and obstructive sleep apnea or obesity-hypoventilation syndrome followed by the hospital pneumology unit. Subjects were included if they were $20-60 \mathrm{y}$ old, had a body mass index of $\geq 30 \mathrm{~kg} / \mathrm{m}^{2}$, were affiliated with the national

\section{QUICK LOOK}

\section{Current knowledge}

Dyspnea is a frequent symptom in obese patients at rest and also in the supine position. Studies have found discrepant results regarding the changes in static lung volumes from the sitting to the supine position. However, the contribution of expiratory flow limitation and closing volume has not been taken into account in most of these results.

\section{What this paper contributes to our knowledge}

Twenty-one obese subjects in stable condition were investigated in the sitting and then in the supine position by using single-breath nitrogen washout to assess closing volume and the negative expiratory pressure to assess expiratory flow limitation. The magnitude of orthopnea increased with the heterogeneity of the distribution of ventilation in seated subjects without expiratory flow limitation.

health insurance program, and gave signed, written, informed consent for participating in the study.

Patients were not included if they met any of the following exclusion criteria: pregnant women; people under guardianship; people under legal protection measures; patients with restrictive or obstructive ventilator impairment from any other concomitant respiratory disorder or left heart failure assessed with clinical, functional, and radiological investigations, including echocardiography; and individuals who refused to participate.

\section{Procedures}

The study was prospective, physiologic, short-term, and interventional and was conducted in the pulmonary function test laboratory of our hospital. The protocol was approved by our institutional ethics committee (Comité de Protection des Personnes Lyon Sud-Est IV) on January 26, 2010. The study was conducted according to French law 2004-806 of the public health code (August 9, 2004) for biomedical research, the ICH Topic E6 Guideline for Good Clinical Practice, French law 2004-801 (August 6, 2004) for freedom and personal electronic data, and the 1964 Declaration of Helsinki in its last revised version (Seoul 2008). During the study, the investigators were always present to take care of the subjects.

Age, sex, body mass index, 6-point Medical Research Council chronic dyspnea scale score, ${ }^{13}$ OSA or obesityhypoventilation syndrome, and smoking status were recorded. The Medical Research Council dyspnea scale in- 
cludes the following stages from 5 to $0: 5=$ too breathless to leave the house; $4=$ need to stop for breath every few minutes when walking on level ground; $3=$ need to stop when walking at own pace or walking more slowly than most people of the same age; 2 = breathless when hurrying on level ground or walking on a slight incline; $1=$ breathless only after strenuous exercise; $0=$ none of these.

Then, after the study aim and design had been explained to the subject, the order of body position was randomly allocated from a computer-generated randomization table. Each position was applied for $30 \mathrm{~min}$ before the measurements were taken in the following order.

Dyspnea was assessed from the nonlinear Borg scale ${ }^{14}$ using a score sheet (see the supplementary Table 1 at http://www.rcjournal.com). The Borg scale is a rating of perceived dyspnea on a scale of $0-10$ that quantifies the intensity of dyspnea during activity. We first explained to subjects that the goal was to assess their current stage of dyspnea. Then we asked them to check the number on the evaluation form that best matched their current sensation of dyspnea. Lung volumes were measured according to standard recommendations. ${ }^{15} \mathrm{FEV}_{1}$ and $\mathrm{FVC}$ were obtained using standard spirometry (Body Box 5500, Medisoft, Belgium).

FRC, ERV, inspiratory capacity, residual volume, and total lung capacity (TLC) were measured using the multiple-breath helium dilution technique (Body Box 5500). Two to three measurements of FRC were taken for each subject and averaged. This was also done for ERV, inspiratory capacity, residual volume, and TLC. Tidal volume $\left(\mathrm{V}_{\mathrm{T}}\right)$ and breathing frequency were computed from the FRC recording.

Expiratory flow limitation was assessed by performing a negative expiratory pressure test (Body Box 5500) as described previously. ${ }^{16}$ Basically, a $-5 \mathrm{~cm} \mathrm{H}_{2} \mathrm{O}$ pressure was applied at the mouth during tidal expiration over 3-5 nonconsecutive breaths, with the nose clipped. The flowvolume curves, before (baseline breath) and during (test breath) application of negative expiratory pressure, were superimposed. Expiratory flow limitation was present whenever the expiratory flow of the test breath did not depart from its baseline value. Expiratory flow limitation was quantified as the percentage of $\mathrm{V}_{\mathrm{T}}$ with no change in expiratory flow between baseline and test breath.

Closing volume was measured using the single-breath nitrogen expiration test ${ }^{17}$ (Vmax device, SensorMedics, France). Subjects were asked to exhale to residual volume and then to inhale up to TLC while they were switched to pure oxygen. Then they were instructed to slowly exhale back to residual volume maintaining a constant expiratory flow at around $0.2-0.5 \mathrm{~L} / \mathrm{s}$. From the plot of nitrogen concentration against expired volume from TLC to residual volume, closing volume was defined as the volume encompassing the onset of phase IV (abrupt increase in nitrogen concentration) to residual volume. The closing capacity was equal to closing volume plus residual volume. The opening capacity was defined as TLC minus volume at the onset of phase IV. The slope of phase III (percentage nitrogen concentration/L), which quantifies the uneven distribution of ventilation, was computed during the linear part of the relationship of nitrogen concentration with expired volume. The maneuver was repeated up to 3 times, and mean values were used.

\section{Data Analysis}

Values are presented as median (interquartile range [IQR]). Lung volumes were expressed as the percent predicted using standard equations. ${ }^{18}$ Closing volume was presented as an absolute value. In cases where there was no clear phase IV during the single-breath nitrogen expiration test, the value for closing volume was set to 0 , and that value of 0 was used in the analysis. Opening capacity, closing volume/VC, closing capacity/TLC, and the slope of phase III were expressed as absolute values.

Orthopnea was defined as any increase in Borg score in the supine position compared with its value in the sitting position. Because the first position was randomly allocated, the absence of statistical carryover effect was tested between subjects in the supine and then the sitting position and subjects positioned in the reverse order. The primary end points were the single-breath nitrogen expiration testrelated variables, namely closing volume, closing volume/ VC, closing capacity, closing capacity/TLC, opening capacity, and slope of phase III. The other variables were secondary end points. Comparisons of continuous variables between orthopnea and non-orthopnea groups in the sitting position were made using a non-paired Mann-Whitney U test. In each orthopnea and non-orthopnea group, comparisons of continuous variables between the sitting and supine positions were made using the paired Wilcoxon signed-rank test. For categorical variables, we used the Fisher exact test to compare groups. Correlations of changes between the sitting and the supine positions for closing volume/VC, closing capacity/TLC, slope of phase III, and opening capacity in subjects with or without expiratory flow limitation in the sitting position were estimated using the Spearman coefficient with its 95\% CI. The reproducibility of the measurement of the closing volume was assessed by the intraclass correlation with its $95 \%$ CI. ${ }^{19}$ $P<.05$ was used as the statistical significance threshold. Statistical analyses were performed using SPSS (SPSS 17.0, Chicago, Illinois) and R 3.2.0 (R: A Language and Environment for Statistical Computing, R Foundation for Statistical Computing, Vienna, Austria). 


\section{Mechanisms of Orthopnea in Stable Obese Subjects}

Table 1. Individual Data on Age, Sex, Body Mass Index, Chronic Dyspnea Score, and Orthopnea Group Based on the Borg Scale in 21 Obese Subjects

\begin{tabular}{|c|c|c|c|c|c|c|c|}
\hline Subject & Age, y & Sex & BMI, $\mathrm{kg} / \mathrm{m}^{2}$ & $\begin{array}{l}\text { MRC Chronic } \\
\text { Dyspnea Scale }\end{array}$ & Borg Scale Sitting & Borg Scale Supine & Orthopnea \\
\hline 1 & 59 & Female & 32 & 0 & 0.0 & 1.0 & Yes \\
\hline 2 & 26 & Female & 39 & 0 & 0.0 & 0.0 & No \\
\hline 3 & 49 & Male & 34 & 0 & 0.0 & 3.0 & Yes \\
\hline 4 & 59 & Female & 45 & 2 & 0.0 & 5.0 & Yes \\
\hline 5 & 53 & Male & 37 & 1 & 0.0 & 0.5 & Yes \\
\hline 6 & 49 & Male & 44 & 2 & 0.0 & 4.0 & Yes \\
\hline 7 & 55 & Male & 39 & 1 & 0.5 & 0.5 & No \\
\hline 8 & 58 & Female & 42 & 2 & 0.0 & 0.5 & Yes \\
\hline 9 & 53 & Male & 40 & 2 & 0.5 & 2.0 & Yes \\
\hline 10 & 56 & Female & 40 & 1 & 3.0 & 3.0 & No \\
\hline 11 & 57 & Male & 39 & 1 & 0.0 & 0.0 & No \\
\hline 12 & 60 & Female & 39 & 2 & 0.0 & 0.5 & Yes \\
\hline 13 & 50 & Female & 42 & 1 & 0.5 & 2.0 & Yes \\
\hline 14 & 56 & Male & 37 & 1 & 0.0 & 0.5 & Yes \\
\hline 15 & 48 & Female & 60 & 2 & 2.0 & 1.0 & No \\
\hline 16 & 56 & Female & 31 & 1 & 0.0 & 0.0 & No \\
\hline 17 & 41 & Female & 39 & 2 & 0.5 & 0.0 & No \\
\hline 18 & 40 & Female & 47 & 2 & 0.5 & 0.5 & No \\
\hline 19 & 54 & Female & 38 & 2 & 0.5 & 0.0 & No \\
\hline 20 & 57 & Female & 40 & 2 & 1.0 & 2.0 & Yes \\
\hline 21 & 58 & Male & 45 & 3 & 1.0 & 3.0 & Yes \\
\hline
\end{tabular}

\section{Results}

\section{Description of the Subjects}

Twenty-one subjects were included and analyzed (Table 1). Median (IQR) values for age, body mass index, and Medical Research Council dyspnea score were $55(49-57)$ y, $39(38-42) \mathrm{kg} / \mathrm{m}^{2}$, and $2(1-2)$, respectively. Median (IQR) values were: $\mathrm{FEV}_{1}=86(76-98) \%$ predicted, $\mathrm{FEV}_{1} / \mathrm{FVC}=77(75-82) \%$, TLC $=89(80-$ $100) \%$ predicted, closing volume $=91(85-106) \%$ predicted, inspiratory capacity $=116(107-127) \%$ predicted, $\mathrm{FRC}=71(66-86) \%$ predicted, ERV $=25(19-53) \%$, and residual volume $=88(75-103) \%$ predicted. Nineteen subjects had OSA that was treated by nasal continuous positive pressure in all but 3 . Four subjects had obesityhypoventilation syndrome, 2 of them receiving nocturnal noninvasive ventilation. Ten subjects were neversmokers, 9 were past smokers, and 2 were current smokers.

Twelve subjects ( 6 women) were orthopneic, and 9 subjects (7 women) were not (see Table 1). In orthopneic and non-orthopneic subjects, sitting and supine median (IQR) Borg scores were $0.5(0.0-0.5)$ versus $2(0.5-3.0)$ and 0.0 $(0.0-0.5)$ versus $0.0(0.0-0.5)$, respectively. The carry- over effect was not significant regarding the Borg score. The distribution of sex was not different between orthopneic and non-orthopneic subjects; nor were the median (IQR) values of body mass index (39 [37-42] vs 39 [38$\left.40] \mathrm{kg} / \mathrm{m}^{2}, P=.97\right)$. Orthopneic subjects tended to be older than non-orthopneic subjects $(57$ [52-58] y vs 54 [41-56] y, $P=.06)$. Neither the orthopneic nor the nonorthopneic groups differed significantly for pulmonary function tests in the sitting position (Table 2). The same was true for $\mathrm{V}_{\mathrm{T}}(0.925[0.570-0.975] \mathrm{L}$ vs 0.840 [0.730 $0.910] \mathrm{L}, P=.72)$ and breathing frequency $(17[15-21]$ sitting vs 18 [16-24] breaths/min supine, $P=.75)$, in orthopneic and non-orthopneic subjects, respectively. Six orthopneic subjects and 5 non-orthopneic subjects exhibited expiratory flow limitation in the sitting position $(P=.81)$ over $8 \pm 14 \%$ versus $20 \pm 31 \%$ of $\mathrm{V}_{\mathrm{T}}$, respectively $(P=.71)$.

Three subjects in the orthopneic group and 2 in the non-orthopneic group did not exhibit a clear phase IV during the single-breath nitrogen expiration test. These five subjects did not differ from the 16 with detectable phase IV for any of the variables assessed. Sitting closing volume averaged $0.240(0.110-0.660) \mathrm{L}$ versus 0.310 $(0.010-0.900) \mathrm{L}(P=.62)$ in the orthopneic and nonorthopneic groups, respectively. The intraclass correlation 
Table 2. Pulmonary Function Tests in the Seated Position in Orthopneic and Non-Orthopneic Obese Subjects

\begin{tabular}{lccc}
\hline \hline \multicolumn{1}{c}{ PFT Variable } & $\begin{array}{c}\text { Orthopneic } \\
(n=12)\end{array}$ & $\begin{array}{c}\text { Non-Orthopneic } \\
(n=9)\end{array}$ & $P$ \\
\hline FVC & $86(82-99)$ & $95(78-112)$ & .48 \\
FEV $_{1}$ & $84(78-94)$ & $90(65-100)$ & .72 \\
Total lung capacity & $87(72-100)$ & $89(87-99)$ & .36 \\
Functional residual capacity & $73(59-86)$ & $71(67-77)$ & .97 \\
Inspiratory capacity & $111(99-121)$ & $117(107-136)$ & .18 \\
Expiratory volume reserve & $24(19-49)$ & $52(20-60)$ & .37 \\
Residual volume & $88(77-104)$ & $98(75-103)$ & .94 \\
\end{tabular}

Data are median (interquartile range) percent predicted. No difference between groups was statistically significant.

PFT $=$ pulmonary function test

$\mathrm{FVC}=$ forced vital capacity

for the measurement of the closing volume was 0.77 (95\% CI $0.44-0.92)$ in the sitting position and 0.89 (95\% CI 0.72-0.96) in the supine position. As shown in Table 3, the other variables related to the single-breath nitrogen expiration test were not different between the 2 groups.

Table 3. Results of the Single-Breath Nitrogen Expiration Test in Orthopneic and Non-Orthopneic Obese Subjects Measured in the Seated Position

\begin{tabular}{lccr}
\hline \hline \multicolumn{1}{c}{ Variable } & $\begin{array}{c}\text { Orthopneic } \\
(n=12)\end{array}$ & $\begin{array}{c}\text { Non-Orthopneic } \\
(n=9)\end{array}$ & $P$ \\
\hline $\begin{array}{c}\text { Closing volume/vital } \\
\text { capacity, \% }\end{array}$ & $13(3-18)$ & $13(0-22)$ & .94 \\
$\begin{array}{l}\text { Closing capacity, L } \\
\text { Closing capacity/total }\end{array}$ & $2.210(1.850-2.500)$ & $1.940(1.530-2.620)$ & .55 \\
$\quad$ lung capacity, \% & $47(37-50)$ & $40(36-48)$ & .59 \\
$\begin{array}{l}\text { Opening capacity, L } \\
\text { Slope of phase III, \%/L }\end{array}$ & $2.450(1.730-4.170)$ & $2.430(1.181-3.730)$ & $>.99$ \\
\end{tabular}

Data are median (interquartile range) of the absolute values of the variables. No difference between groups was statistically significant.

\section{Changes in Single-Breath Nitrogen Expiration Test Between Sitting and Supine Position in Orthopneic and Non-Orthopneic Subjects}

For the orthopneic subjects in the supine position, median (IQR) closing volume did not change $(0.336$ [0.120 $0.588] \mathrm{L}$ ) compared with the value for the sitting position (0.240 [0.113-0.660], $P=.48$ vs sitting). The same was true for the other variables pertaining to the single-breath nitrogen expiration test (Fig. 1).

For the non-orthopneic subjects, there was a significant decrease in the slope of phase III from 1.67 (1.33-3.60) to $1.40(1.25-1.66) \% \mathrm{~N} 2 / \mathrm{L}(P=.008)$ in the sitting and supine position, respectively (see Fig. 1). The median values of closing volume, closing volume/vital capacity, closing capacity/TLC, and opening capacity did not change between the 2 positions (see Fig. 1). Among the 11 nonexpiratory flow limitation subjects in the sitting position, all but 2 became flow-limited in the supine position. The change in $\mathrm{FEV}_{1}$, closing volume, inspiratory capacity, FRC, TLC, ERV, residual volume, and tidal expiratory flow limitation $\left(\% \mathrm{~V}_{\mathrm{T}}\right)$ with position was not statistically significantly different between orthopneic and nonorthopneic subjects (not shown).

\section{Relationships of Orthopnea to Changes in Nitrogen Single-Breath Expiration Test-Related Variables With Position}

Among all subjects, there were statistically significant correlations between the Borg score and the slope of phase III ( $\mathrm{r}=0.63,95 \%$ CI $0.23-0.85, P=.002)$ and opening capacity $(\mathrm{r}=-0.47,95 \% \mathrm{CI}-0.80$ to 0.03 , $P=.03$ ) (Table 4). This indicates that the magnitude of orthopnea increased with the heterogeneity of the distribution of ventilation and the reduction in opening capacity in the supine position. The correlations between orthopnea and the other variables of the nitrogen single-breath expi-
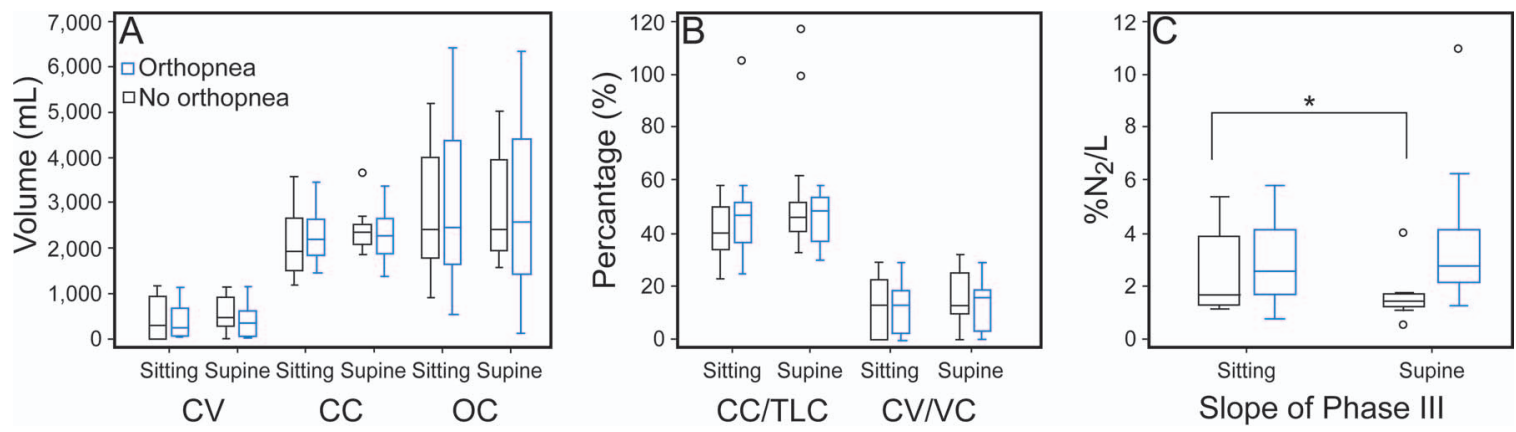

Fig. 1. Box-and-whisker plots of closing volume (CV), closing capacity (CC), and opening capacity (OC) (A); CV/VC and CC/total lung capacity (TLC) (B); and slope of phase III (C) in obese subjects with (green boxes) or without (blue boxes) orthopnea measured in the sitting and in the supine position. ${ }^{*} P=.008$ between sitting and supine position (paired Wilcoxon signed-rank test). Boxes represent the first and third quartiles, center lines denote the median, and whiskers show the highest and lowest values. Open circles represent outliers. 


\section{Mechanisms of Orthopnea in Stable Obese Subjects}

Table 4. Correlations Between Orthopnea and Nitrogen Single-Breath Expiration Test-Derived Variables

\begin{tabular}{lccc}
\hline \hline \multicolumn{1}{c}{ Variable } & All Subjects $(\mathrm{N}=21)$ & Flow-Limited Seated $(n=11)$ & Not Flow-Limited Seated $(n=10)$ \\
\hline Closing volume/vital capacity, \% & $-0.03(-0.47$ to 0.46$)$ & $0.14(-0.53$ to 0.64$)$ & $-0.23(-0.83$ to 0.53$)$ \\
Closing capacity/total lung capacity, \% & $-0.05(-0.49$ to 0.44$)$ & $0.11(-0.46$ to 0.71$)$ & $-0.19(-0.94$ to 0.63$)$ \\
Slope of phase III, \%/L & $0.63(0.23-0.85)^{*}$ & $0.53(-0.05$ to 0.90$)$ & $0.68 \dagger(0.17-0.98)$ \\
Opening capacity, L & $-0.47(-0.80$ to -0.03$) \dagger$ & $-0.55(-0.89$ to 0.06$)$ & $-0.41(-0.96$ to 0.47$)$
\end{tabular}

Data are Spearman correlation $(95 \% \mathrm{CI})$. Correlations were made between changes in the Borg scale from seated to supine position and corresponding changes in the variables listed in the first column for similar position change. Each difference was computed as the value in the supine position minus the value in the sitting position.

$* P=.002$

$\dagger P=.03$.

ration test were not statistically significant. We further expanded this analysis by taking into account expiratory flow limitation in the sitting position for the above correlations (see Table 4). The single statistically significant correlation was observed in the 10 subjects without expiratory flow limitation in the sitting position between Borg score and the slope of phase III $(\mathrm{r}=0.68,95 \%$ CI $0.17-$ $0.98, P=.03$ ).

\section{Discussion}

The main findings of the present study were that: (1) lung function tests, including closing volume, were not significantly different in the sitting position for subjects who did or did not exhibit orthopnea; (2) in orthopneic subjects, closing volume did not significantly change according to their position, whereas in non-orthopneic subjects, the slope of phase III decreased between the sitting and the supine position; and (3) the magnitude of orthopnea correlated to the opening capacity and to the slope of phase III. This is the first study that has assessed the effects of closing volume together with expiratory flow limitation in the sitting and supine positions on orthopnea in obese subjects.

Although the Borg scale has been validated to assess the perception of breathlessness during exercise, we used it in the present study to assess the change in breathlessness between 2 conditions of slight activity. However, others have previously used the Borg scale to assess orthopnea in obese subjects. ${ }^{12}$ In a systematic review on the methods to assess breathlessness in obese subjects, the Borg scale was found reliable. ${ }^{20}$ When using the Borg scale to assess dyspnea, a minimally important difference of 1 unit or more has been suggested. ${ }^{21}$ It is of interest that the median difference between supine and sitting positions in our study was equal to 2 units, making this difference clinically relevant.

The effect of obesity on respiratory function is complex, notably because it is related to the distribution of fat within the body ${ }^{11}$ and consequently to sex. Aging also plays a role because airway closure increases with age. Our sam- ple of subjects is characterized by low ERV values and a high prevalence of expiratory flow limitation (52\%) in the sitting position. Furthermore, all subjects but one in our study had concomitant OSA or obesity-hypoventilation syndrome and, hence, were not healthy obese subjects. In the study by Ferretti et al ${ }^{12}$ of over 46 subjects with massive obesity ( 21 with OSA $=46 \%$ ), the mean ERV was $66 \pm 19 \%$ predicted, and 10 subjects $(22 \%)$ were flowlimited in the sitting position. Orthopnea occurred in 57\% of the present subjects and in $44 \%$ of those investigated by Ferretti et al. ${ }^{12}$ Contrary to the present results, in the study by Ferretti et al, ${ }^{12}$ ERV in the sitting position was significantly lower in orthopneic than in non-orthopneic subjects. The low baseline value of ERV in the sitting position in our study may account for this discrepancy.

Ferretti et $\mathrm{al}^{12}$ found in massively obese subjects that orthopnea was related to the low value of ERV in the sitting position and expiratory flow limitation in the supine position. Our study did not confirm these findings for the reasons discussed above and perhaps due to a type- 2 error in the study. However, the present results expand on the findings of Ferretti et $\mathrm{al}^{12}$ by assessing closing volume in both the sitting and supine positions. We found that the slope of phase III significantly declined in the supine position in non-orthopneic subjects. This suggests that subjects without orthopnea exhibited less heterogeneity in the distribution of ventilation. However, there was no change in the slope of phase III in subjects with orthopnea, and the same was true for the variables related to the single-breath nitrogen expiration test.

Five subjects $(24 \%)$ in our study did not exhibit a detectable phase IV in any position. In 32 healthy obese subjects studied by Benedik et al, ${ }^{11}$ closing volume was measured in 7 of them in whom the closing capacity/FRC ratio significantly decreased between the sitting and the supine position. Therefore, the prevalence of phase IV in a large population of obese subjects is unknown. In subjects with COPD, there was a concomitant increase in the slope of phase III and disappearance in phase IV according to the severity of the Global Initiative for Chronic Obstructive Lung Disease (GOLD) stages. ${ }^{22}$ These findings 
have two implications. First, the more severe the GOLD stage, the more heterogeneous is the distribution of ventilation. Therefore, the critical closing pressures are more widely scattered throughout the lungs, resulting in the disappearance of phase IV. The presence of phase IV implies a less-scattered distribution of critical closing pressures. The second implication relates to the diagnostic clue of the slope of phase III, which would be more sensitive to detect closure than closing volume per se in patients with COPD. Applied to the obese subjects in the present study, these considerations led us to speculate that small airway disease was diffuse.

We found that opening capacity was more sensitive in detecting changes in the distribution of ventilation than the measurement of closing volume per se. This observation is interesting because it makes the single-breath nitrogen washout easier to perform because it avoids exhaling to residual volume.

Our results have shown that it is important to take into account expiratory flow limitation. The presence of expiratory flow limitation indicates that small airway disease is diffuse. ${ }^{23}$ This is the case in COPD patients because the occurrence of sitting expiratory flow limitation correlates with dyspnea ${ }^{13}$ and with GOLD stage. ${ }^{22}$ In obese patients, small airway disease is not expected to be diffuse but rather localized in the most caudal and dorsal parts of the lung. The fact that a substantial number of the present subjects exhibited expiratory flow limitation in the sitting position may have 2 alternative explanations other than diffuse small airway disease. The first is concomitant COPD. This is unlikely because obstructive ventilator impairment was an exclusion criterion. This was confirmed by the pulmonary function tests performed. The second reason is that negative expiratory pressure testing may be invalid in OSA. In awake subjects who snore, with increased upper airway collapsibility, Tantucci et $\mathrm{al}^{24}$ found that the flow during negative expiratory pressure application remained lower than flow during the previous control expiration, a finding reflecting high upper airway resistance. We did not observe this kind of pattern in any of the negative expiratory pressure tests performed on our subjects, indicating that negative expiratory pressure testing accurately assessed intrathoracic flow limitation. It should be noted that others have suggested that the change in peak flow better correlates to the apnea-hypopnea index than the change in volume after application of negative expiratory pressure. ${ }^{25}$ Obesity also favors upper airway collapsibility, but it has been found that negative expiratory pressure testing is a valid means of detecting expiratory flow limitation in OSA-free obese subjects. ${ }^{26}$ Therefore, the most likely explanation for the high prevalence of expiratory flow limitation in the sitting position in our sample of obese subjects is diffuse small airway disease, which supports the closing volume-based argument dis- cussed previously. However, we have no direct evidence of this hypothesis.

\section{Limitations}

The present study included a small number of subjects, which, as discussed above, may have induced a type-2 error. Furthermore, our subjects also had OSA or obesityhypoventilation syndrome, which limits the generalizability of the present results to the entire population of healthy obese individuals. Furthermore, the significant reduction in the slope of phase III between the sitting and supine position only in a subset of subjects may be a result obtained without adjustment for a multiple comparison.

In stable obese subjects, magnitude of orthopnea correlated to an increase in the slope of phase III in subjects without expiratory flow limitation. Expiratory flow limitation should be taken into account in obese patients.

\section{ACKNOWLEDGMENTS}

We thank Muriel Rabilloud MD for help with the statistical analysis.

\section{REFERENCES}

1. Ng M, Fleming T, Robinson M, Thomson B, Graetz N, Margono C, et al. Global, regional, and national prevalence of overweight and obesity in children and adults during 1980-2013: a systematic analysis for the Global Burden of Disease Study 2013. Lancet 2014; 384(9945):766-781.

2. Ogden CL, Carroll MD, Kit BK, Flegal KM. Prevalence of childhood and adult obesity in the United States, 2011-2012. JAMA 2014; 311(8):806-814.

3. Flegal KM, Kit BK, Orpana H, Graubard BI. Association of allcause mortality with overweight and obesity using standard body mass index categories: a systematic review and meta-analysis. JAMA 2013;309(1):71-82.

4. Beuther DA, Sutherland ER. Overweight, obesity, and incident asthma: a meta-analysis of prospective epidemiologic studies. Am J Respir Crit Care Med 2007;175(7):661-666.

5. Peppard PE, Young T, Barnet JH, Palta M, Hagen EW, Hla KM. Increased prevalence of sleep-disordered breathing in adults. Am J Epidemiol 2013;177(9):1006-1014.

6. Nowbar S, Burkart KM, Gonzales R, Fedorowicz A, Gozansky WS, Gaudio JC, et al. Obesity-associated hypoventilation in hospitalized patients: prevalence, effects, and outcome. Am J Med 2004;116(1):1-7.

7. Jones RL, Nzekwu MM. The effects of body mass index on lung volumes. Chest 2006;130(3):827-833.

8. Babb TG, Ranasinghe KG, Comeau LA, Semon TL, Schwartz B. Dyspnea on exertion in obese women: association with an increased oxygen cost of breathing. Am J Respir Crit Care Med 2008;178(2):116-123.

9. Watson RA, Pride NB. Postural changes in lung volumes and respiratory resistance in subjects with obesity. J Appl Physiol 2005;98(2): 512-517.

10. Yap JC, Watson RA, Gilbey S, Pride NB. Effects of posture on respiratory mechanics in obesity. J Appl Physiol 1995;79(4):1199-1205.

11. Benedik PS, Baun MM, Keus L, Jimenez C, Morice R, Bidani A, Meininger JC. Effects of body position on resting lung volume in overweight and mildly to moderately obese subjects. Respir Care 2009;54(3):334-339. 


\section{Mechanisms of Orthopnea in Stable Obese Subjects}

12. Ferretti A, Giampiccolo P, Cavalli A, Milic-Emili J, Tantucci C. Expiratory flow limitation and orthopnea in massively obese subjects. Chest 2001;119(5):1401-1408.

13. Eltayara L, Becklake MR, Volta CA, Milic-Emili J. Relationship between chronic dyspnea and expiratory flow limitation in patients with chronic obstructive pulmonary disease. Am J Respir Crit Care Med 1996;154(6 Pt 1):1726-1734.

14. Borg GA. Psychophysical bases of perceived exertion. Med Sci Sports Exerc 1982;14(5):377-381.

15. Wanger J, Clausen JL, Coates A, Pedersen OF, Brusasco V, Burgos F, et al. Standardisation of the measurement of lung volumes. Eur Respir J 2005;26(3):511-522.

16. Koulouris NG, Valta P, Lavoie A, Corbeil C, Chassé M, Braidy J, Milic-Emili J. A simple method to detect expiratory flow limitation during spontaneous breathing. Eur Respir J 1995;8(2):306-313.

17. McCarthy DS, Spencer R, Greene R, Milic-Emili J. Measurement of "closing volume" as a simple and sensitive test for early detection of small airway disease. Am J Med 1972;52(6):747-753.

18. Pellegrino R, Viegi G, Brusasco V, Crapo RO, Burgos F, Casaburi $\mathrm{R}$, et al. Interpretative strategies for lung function tests. Eur Respir $\mathrm{J}$ 2005;26(5):948-968.

19. Shrout PE, Fleiss JL. Intraclass correlations: uses in assessing rater reliability. Psychol Bull 1979;86(2):420-428.
20. Gerlach Y, Wiliams MT, Coates AM. Weighing up the evidence: a systematic review of measures used for the sensation of breathlessness in obesity. Int J Obes 2013;37(3):341-349.

21. Cazzola M, MacNee W, Martinez FJ, Rabe KF, Franciosi LG, Barnes PJ, et al. Outcomes for COPD pharmacological trials: from lung function to biomarkers. Eur Respir J 2008;31(2):416-469.

22. Gennimata SA, Palamidas A, Karakontaki F, Kosmas EN, Koutsoukou A, Loukides S, et al. Pathophysiology of evolution of small airways disease to overt COPD. COPD 2010;7(4):269-275.

23. Milic-Emili J, Torchio R, D’Angelo E. Closing volume: a reappraisal (1967-2007). Eur J Appl Physiol 2007;99(6):567-583.

24. Tantucci C, Duguet A, Ferretti A, Mehiri S, Arnulf I, Zelter M, et al. Effect of negative expiratory pressure on respiratory system flow resistance in awake snorers and nonsnorers. J Appl Physiol 1999; 87(3):969-976.

25. Insalaco G, Romano S, Marrone O, Salvaggio A, Bonsignore G. A new method of negative expiratory pressure test analysis detecting upper airway flow limitation to reveal obstructive sleep apnea. Chest 2005;128(4):2159-2165

26. Baydur A, Wilkinson L, Mehdian R, Bains B, Milic-Emili J. Extrathoracic expiratory flow limitation in obesity and obstructive and restrictive disorders: effects of increasing negative expiratory pressure. Chest 2004;125(1):98-105.

This article is approved for Continuing Respiratory Care Education credit. For information and to obtain your CRCE

(free to AARC members) visit www.rcjournal.com

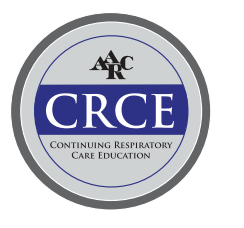

